\title{
EU food agency circles round biotech
}

There have been a number of high-level pronouncements within the European Commission (EC; Brussels) heralding a new European Union (EU)-wide food safety agency, an agency that would, among other things, almost certainly regulate foods containing genetically modified (GM) ingredients. But the wholesale reorganization within the EC following the mass resignation of commissioners in early 1999 (Nature Biotechnology $17,418,1999)$ has hampered any advance in the plans. With the new commission finally in place at the end of September, the food agency is likely to come off the back burner, but it remains unclear under which department responsibility will fall.

"Genetically modified organisms and food safety are high on the commission's priority list," says Paul Muys, the agricultural biotechnology spokesperson for the European biotechnology trade body, EuropaBio (Brussels). He points out that during the recent confirmation hearing for new European commissioners, members of the European Parliament (Strasbourg, France) grilled several candidates-including those with responsibility for the environment, industry, trade, and consumer protection-over GM organisms and GM food in particular.

Senior officials at the EC have been flirting with the idea of an agency for some time. In 1996, a proposal that the food and veterinary office (Grange, Ireland) should become an independent agency was rejected by national European governments. The commissioner then responsible for consumer affairs, Emma Bonino, had rejected the suggestion that the US Food and Drug Administration (FDA; Rockville, MD) would be a suitable model for the EU. That model nevertheless resurfaced in December 1998 when the European agriculture commissioner, Franz Fischler, again put forward the idea of a single body deciding food safety issues. He said that the body might follow "the US example [of the FDA] but ... based on European thinking." Fischler also suggested that a possible model be based on the coordinated, devolving way that pharmaceuticals were being regulated at the European Medicines Evaluation Agency (EMEA; London), the drug equivalent of the FDA.

Both Bonino's and Fischler's comments preceded the recent breakup of the commission, but the food agency concept itself has certainly survived the transition. In a speech at the European Parliament in Strasbourg at the end of July, the new president-designate of the EC, Romano Prodi, revisited the idea. He said that he wanted "to take the initiative and look toward the idea of an independent European food and drug agency to help win back consumer confidence." $\mathrm{He}$ argued that the European public has lost confidence in national and European food and drug regulators, governments, and scientists, implying that an independent food agency would be a way to rebuild credibility.

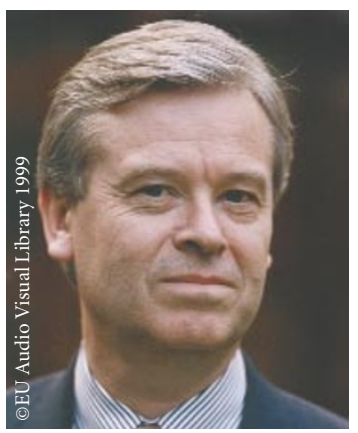

David Byrne, commissioner for health and consumer protection, the most likely administrative home for the food agency.

In advance of the new commission bedding down, Gillian Asprey of Consumers in Europe (London), a group that looks at the impact of European legislation on consumers, is skeptical about the politician's announcements. "[The food agency] is the sort of thing people stand up and talk about at conference," she says. "But I am not aware that anything is actually happening at the moment in practical terms."

One of the leading candidates for administering a European food agency was the industry directorate, DGIII. DGIII was responsible for the establishment in 1995 of the highly regarded EMEA in London, and was also responsible for the introduction of the EU's Novel Foods regulation. However, the EC's reorganization has redistributed important parts of the industry portfolio to other parts of the commission, leaving a more focused department for the incoming industry commissioner, Erkki Liikanen (now the commissioner for enterprise and information society). Nevertheless, Tony Venables, head of the European Citizen's Action Service (ECAS; Brussels), a nongovernmental organization that has made its own proposals for a "European Citizens' Institute for Food and Health," believes that directorate might still be involved if the food agency arose within an expanded EMEA.

Commission reorganization has also reduced the likelihood that a food agency would fall within the orbit of Franz Fischler at agriculture, one of the few commissioners to retain their posts. Fischler is an enthusiast for the agency, but one of his department's key responsibilities - for the administration and enforcement of veterinary regulations, which encompasses safety throughout the food chain-has been passed on to DGXXIV, the directorate-general for health and consumer protection.

Indeed, DGXXIV is the most likely administrative home for the food agency. It now has responsibilities both for the scientific committees that advise the commission, for veterinary and phytosanitary inspections, and for food safety.

DGXXIV has been consolidating its qualifications for handling the agency. In 1997, it set up a scientific steering committee (SSC) in consumer health and food safety that has been heavily involved in formulating the commission's response to the crisis over BSE and other transmissible spongiform encephalopathies. But one of its working groups has also been thoroughly exercised in exploring "the evolution of scientific advice to address emerging health issues," using risk assessment of GM organisms as a case study. Most recently, DGXXIV has asked a group of three academics-Fritz Kemper of Münster University, Philip James of the Rowett Institute (Aberdeen, UK), and Gérard Pascal, director of the Centre National d'Etudes et de Recommendations sur la Nutrition et l'Alimentation (Paris, France) - to review the range of advice that is provided to the EC through its seven scientific advisory committees. The three will report their findings in November. Philip James was the author of the preliminary blueprint for the UK's Food Standards Agency. As director, James first publicly supported and then retracted his support for the now controversial work on transgenic potatoes conducted by Arpad Pusztai at the Rowett Institute.

In his confirmatory hearing at the beginning of September, the new DGXXIV commissioner for health and consumer protection, David Byrne, responded to questions from Green members of the European Parliament concerning GM organisms by saying that he would commission scientific reports to determine any risks to human health. He added that, in case of any doubt, he would apply the precautionary principle and ban the product from the market.

Meanwhile the UK, France, Belgium, and other member states are well advanced in their plans for national food control agencies. The bill establishing the UK Food Standards Agency could become law by the end of October, and advertisements for its director and other staff were being placed in September. John Hodgson 